\title{
In reply: Further considerations on competence by design: when opportunity stops knocking
}

\author{
Jason Waechter, MD, FRCP(C)
}

Received: 22 November 2016/ Accepted: 24 November 2016/Published online: 9 December 2016

(C) Canadian Anesthesiologists' Society 2016

\section{To the Editor,}

I appreciate and agree with the comments made by Drs Shorten and Levine. ${ }^{1}$ The introduction of competence by design appears to require a significant increase in data collection relevant to trainee performance and assessment. Increasing the efficiency of collecting these data will likely require innovative approaches. Capturing the data with video cameras is certainly one option. Confidentiality and privacy of information for both the patients and the trainees are factors that will require attention for all data that are collected, regardless of the collection tool. Mapping out learning curves (and forgetting curves) for required areas of competence will certainly require large data sets. Collection and analysis of these large data sets without a significant increase in workload for the instructors and administrators of a curriculum is an important goal. The results could hopefully lead to more efficient, more effective learning strategies. As calls for increased assessment data appear to be inevitable, a sustainable solution for collecting and analyzing the data is paramount.

Competing interest Jason Waechter is the founder of teachingmedicine.com, a medical education website

Editorial responsibility This submission was handled by Dr. Hilary P. Grocott, Editor-in-Chief, Canadian Journal of Anesthesia

\section{Reference}

1. Shorten $G$, Levine $M F$. Further considerations on competence by design: when opportunity stops knocking. Can J Anesth 2017; 64. DOI: $10.1007 / \mathrm{s} 12630-016-0786-8$.
J. Waechter, MD, FRCP(C) ( $\square)$

Departments of Critical Care and Anesthesiology, University of Calgary, Calgary, AB, Canada

e-mail: jwaech@yahoo.ca 